\title{
Testing heat supply networks for heat losses
}

\author{
Anna Mozgova ${ }^{1 *[0000-0001-9761-4655] ~}$ \\ ${ }^{1}$ I. Ulianov Chuvash State University, 428015 Cheboksary, Russia
}

\begin{abstract}
The scope of operations of the branch where the survey was carried out is: transmission and distribution of heat and heating medium to consumers through heat supply networks, maintaining the proper quality and amount of thermal power and heating medium supplied, ensuring contractual activities with heat consumers, as well as control of compliance with the consumption regimes stipulated by contracts, ensuring payments from consumers for supplied heat and heating medium, development and implementation of measures ensuring maximum efficiency of heat supply activities. The purpose of the work performed is to determine the actual heat losses through the thermal insulation of the surveyed heating networks and to compare them with normative values. The article presents an analysis of materials on the heat supply system; test findings for actual heat losses in a heat supply pipeline; calculation of actual heat losses for each section and their adjustment to average annual operating conditions of the given heat supply network; comparison of calculation results with normative characteristics. The test findings are used in developing the output performance for the «Heat Loss» indicator and in setting of norms for operating heat losses. The heat supply source for the heat pipeline is the CHP-plant. The pipelines are routed above ground on high and low supports, as well as in crawl ways. The thermal insulation of the pipelines is mainly made of $50 \mathrm{~mm}$ blankets of mineral wool and is typical for heat supply networks. In overhauls of heat supply networks, polyurethane foam is partly used as thermal insulation.
\end{abstract}

Keywords. Thermal power, heat losses, heat supply networks, CHP-plant, testing heat supply networks, actual losses, normative losses, thermal insulation.

\section{Introduction}

The actual operating heat losses are determined experimentally through carrying out thermal tests on the heat supply network. The target of the tests is to determine the heat losses for various types of routing and design of the pipeline insulation that are specific to the heat network in question. Based on the test results, the insulation condition of the tested pipelines under the specific routing operating conditions is assessed [1-4]. The tests were performed for the network sections with the routing type and the insulation design is the characteristic of the given network, which facilitates expansion of the test results to the heating network as a whole [5-9].

The immediate task of testing water-based heating networks is to determine the actual heat losses through the thermal insulation of heat network sections determined for testing under the selected mode and to compare them with normative values of heat losses for the

${ }^{*}$ Corresponding author: mozgova-energo@yandex.ru 
same sections of the heat supply network. Determination of heat losses in heat supply networks through thermal insulation is an important practical task. Levelizing of the heat losses at the heating network pipeline section and cylindrical tanks based on the thermal conductivity laws is presented in papers [14-18].

Determination of heat losses based on thermal tests was deduced in accordance with the requirements of RD 34.09.255-97 «Procedural Guidelines for the Determination Thermal Losses in Piped Hot Water Heat Supply Networks»». Energy survey of heat supply systems is considered in papers [19-22].

The thermal power and heating medium source are the CHP-plant. The supplied heat is quality and flow rate controlled according to the time-temperature chart of $130-65^{\circ} \mathrm{C}$ with a peak lopping of $115-65^{\circ} \mathrm{C}$.

The heat supply system is closed. Consumers are connected within a dependent system.

The connected maximum hourly load is $2970.71 \mathrm{Gcal} / \mathrm{h}$, including: for heating - 2296.03 $\mathrm{Gcal} / \mathrm{h}$; for hot water supply $-674.0 \mathrm{Gcal} / \mathrm{h}$; for process needs $-0.15 \mathrm{Gcal} / \mathrm{h}$.

There are 125 central heating substations (CHS) and 5 transfer pumping stations (TPS) currently in operation. The heat supply networks being currently under lease are 1,381.619 $\mathrm{km}$ long in single-pipe enumeration, including: water pipelines $-1375.729 \mathrm{~km}$, comprising $87.348 \mathrm{~km}$ derelict ones; steam piping $-5.890 \mathrm{~km}$.

The assumed outdoor temperature for heating engineering is $32{ }^{\circ} \mathrm{C}$.

The heating season lasts 5160 hours, the summer period is 3240 hours and the repair period is 360 hours.

\section{Materials and methods}

The tests should be carried out on the sections of the heat supply network whose installation type and thermal insulation design are representative features of the given network.

Table 1. Material characteristic of the heat supply network sections under test (in single-pipe enumeration).

\begin{tabular}{|c|c|c|c|c|c|c|}
\hline $\begin{array}{l}\text { Network } \\
\text { section }\end{array}$ & $\begin{array}{l}\text { Installation type, } \\
\text { design of the } \\
\text { thermal insulation }\end{array}$ & $\begin{array}{c}\text { Year of } \\
\text { installation or } \\
\text { replacement }\end{array}$ & $\begin{array}{c}\text { External } \\
\text { diameter, m }\end{array}$ & $\begin{array}{l}\text { Section } \\
\text { length, m }\end{array}$ & $\begin{array}{c}\text { Pipeline } \\
\text { volume, } \\
\mathrm{m}^{3}\end{array}$ & $\begin{array}{c}\text { Material } \\
\text { characteristic, } \\
\mathrm{m}^{2}\end{array}$ \\
\hline $\begin{array}{c}\text { CHP - } \\
\text { downdrop } \\
\text { to the duct }\end{array}$ & $\begin{array}{l}\text { Overhead, mineral } \\
\text { wool blankets }\end{array}$ & up to 1990 & 0.820 & 1949.0 & 979.2 & 1598.2 \\
\hline $\begin{array}{c}\text { Downdrop } \\
\text { to the duct - } \\
\text { TC } 6-9\end{array}$ & $\begin{array}{l}\text { Duct-type, mineral } \\
\text { wool blankets }\end{array}$ & up to 1990 & 0.820 & 480.0 & 241.2 & 393.6 \\
\hline $\begin{array}{l}\text { TC 6-9- } \\
\text { TC 6-13 }\end{array}$ & $\begin{array}{l}\text { Duct-type, mineral } \\
\text { wool blankets }\end{array}$ & up to 1990 & 0.720 & 1118.0 & 430.0 & 805.0 \\
\hline $\begin{array}{l}\text { TC 6-13- } \\
\text { TC 6-15 }\end{array}$ & Duct-type, PU foam & 2012 & 0.720 & 560.0 & 215.4 & 403.2 \\
\hline $\begin{array}{c}\text { TC 6-15- } \\
\text { TC 6-19 }\end{array}$ & Duct-type, blankets & up to 1990 & 0.720 & 662.2 & 254.6 & 476.8 \\
\hline \multirow[t]{2}{*}{$\begin{array}{l}\text { TC 6-19- } \\
\text { TC 6-21A } \\
\end{array}$} & $\begin{array}{c}\text { Duct-type, mineral } \\
\text { wool blankets }\end{array}$ & up to 1990 & 0.630 & 516.0 & 145.8 & 325.1 \\
\hline & & & & 5285.2 & 2266.2 & 4001.9 \\
\hline
\end{tabular}

Representative are those the sections of the heat supply network which make up at least $20 \%$ in the material characteristic of the entire network:

$$
\varphi=\frac{M_{x}}{M_{c}}=\frac{\sum_{x}\left(D_{n} \cdot L\right)}{\sum_{c}\left(D_{n} \cdot L\right)}>0,2
$$

here $M_{x}$ - material characteristic for the feeding or return piping of the network summed over all sections with a given installation type and thermal insulation design, $\mathrm{m}^{2} ; M_{c}$ - material 
characteristic for the feeding or return piping of the network summed over the entire network, $\mathrm{m}^{2} ; D_{n}$ - outer pipe diameter within one network section (in the feeding or return pipeline with equal pipe diameters), $\mathrm{m} ; L$ - length of the network section, $\mathrm{m}$.

The material characteristic of the sections of heat supply network under test is stated in Table 1.

The basic parameters have been determined through calculation. These are the water temperature in the feeding pipeline and the water flow rate in the initial section of the circulation loop under test. Besides, the expected water temperature in the return piping and make-up water flow rate during the tests has been calculated, as well as the approximate duration of the tests.

Water temperature in the feeding $t_{f . t}$ and return $t_{r . t}$ pipelines of the tested loop has been determined by formulae, ${ }^{\circ} \mathrm{C}$ :

$$
\begin{gathered}
t_{f . t}=\frac{t_{f}^{a . a}+t_{r}^{a . a}}{2}+\frac{\Delta t_{t}}{2}+t_{e . t}-t_{e}^{a . a} \\
t_{r . t}=t_{f . t}-\Delta t_{t}=\frac{t_{f}^{a . a}+t_{r}^{c p . e}}{2}-\frac{\Delta t_{t}}{2}+t_{e . t}-t_{e}^{a . a}
\end{gathered}
$$

here $t_{f}^{a . a}$ and $t_{r}^{a . a}$ - annual average water temperatures in the feeding and return pipelines of the network under test, ${ }^{0} \mathrm{C}$, calculated as the arithmetic average of the monthly average temperatures for network water determined as per the approved operational temperature diagram at the monthly average ambient air temperatures; $t_{\text {e.t }}$ - expected ambient temperature averaged over all sections of the loop during the test, ${ }^{\circ} \mathrm{C} ; t_{e}{ }^{a . a}-$ annual average ambient temperature averaged over all sections of the loop, ${ }^{\circ} \mathrm{C}$.

The expected average ambient temperature over all sections of the loop during the tests is determined according to the formula, ${ }^{\circ} \mathrm{C}$ :

$$
t_{e . t}=\frac{t_{g . t}^{m . a} M_{u n d}+t_{a . t}^{m . a} M_{a b}}{M_{\kappa}}
$$

here $t_{\text {g.t }}{ }^{m \cdot a}$ and $t_{a . t}{ }^{m . a}$ - respectively, the average temperature of the ground at the middle level of the heat pipeline axis and of the ambient air throughout the month of the testing period, ${ }^{0} \mathrm{C} ; M_{\text {und }}$ and $M_{a b}$ - material characteristics for the feeding or return pipeline over all sections of underground and above-ground installation, respectively, located within the loop under test, $\mathrm{m}^{2} ; M_{k}$ - aggregate material characteristics for the feeding or return pipeline over all loops under test, $\mathrm{m}^{2}$.

Calculated water consumption $G_{t}$, circulating over the tested loop, is accepted considering the estimated value of heat losses for the loop under the test conditions, which has been calculated by the formula, $\mathrm{kcal} / \mathrm{h}$ :

$$
Q_{t}=\sum_{a b}\left(q_{n . f . t}+q_{n . r . t}\right) \cdot \beta \cdot l+\sum_{\text {und }} q_{n . t} \cdot \beta \cdot l
$$

here $\beta$ - local loss factor, considering the heat loss in the valves, supports and compensating pipes. It is applied according to regulation documents for the duct-type underground and aboveground cable installation, depending on the diameter of the nominal bore of the pipelines (150 $\mathrm{mm}$, at the least $\beta=1.15) . q_{n . t}-$ specific heat losses of a given heat supply network for each underground pipeline diameter in the thermal test mode, $\mathrm{kcal} /(\mathrm{m} \cdot \mathrm{h}) ; q_{n . f . t}$ and $q_{n . r . t}-$ specific heat losses of a given heat supply network in the feeding and return pipeline, respectively, for each diameter of above-ground pipeline in the thermal test mode, $\mathrm{kcal} /(\mathrm{m} \cdot \mathrm{h})$.

The specific heat losses for underground and above-ground installations are determined considering the normative values for heat losses in the thermal mode and circulation loop during tests according to formulae, $\mathrm{W} / \mathrm{m}$ or $\mathrm{kcal} /(\mathrm{m} \cdot \mathrm{h})$ :

$$
q_{f . t}=q_{n} \frac{t_{f . t}^{a . a}+t_{r . t}^{a . a}-2 t_{g . t}^{m . a}}{t_{f}^{a . a}+t_{r}^{a . a}-2 t_{g}^{a . a}},
$$




$$
\begin{gathered}
q_{n . f . t}=q_{n . f} \frac{t_{f . t}^{a . a}-t_{a . t}^{m . a}}{t_{f}^{a . a}-t_{a}^{a . a}}, \\
q_{n . r . t}=q_{n . r} \frac{t_{r . t}^{a . a}-t_{a . t}^{m . a}}{t_{r}^{a . a}-t_{a}^{a . a}} .
\end{gathered}
$$

The values $q_{n}, q_{n . f}$ and $q_{n . r}$ are adopted according to the norms of heat flow density according to the requirements of Decree of the Ministry of Energy of the Russian Federation № 325 dated December 30, 2008 «On work arrangement in the Ministry of Energy of the Russian Federation on approval of norms of process losses during heat transfer», at average annual temperatures of network water and environment.

The average water temperatures in the test mode in the feeding and return pipelines of the tested loop, respectively, are determined according to formulae, ${ }^{\circ} \mathrm{C}$ :

$$
\begin{aligned}
& t_{f . t}^{a . a}=\frac{t_{f}^{a . a}+t_{r}^{a . a}}{2}+\frac{\Delta t_{t}}{4}+t_{e . t}-t_{e}^{a . a} \\
& t_{r . t}^{a . a}=\frac{t_{f}^{a . a}+t_{r}^{a . a}}{2}-\frac{\Delta t_{t}}{4}+t_{e . t}-t_{e}^{a . a}
\end{aligned}
$$

The rated water flow in the circulation loop assigned for the test period is determined by the formula, $t / h$ :

$$
G_{t}=\frac{Q_{t}}{c \cdot \Delta t_{t}} \cdot 10^{-3}
$$

here $c$ - specific heat capacity of the grid water, assumed to be $1.0 \mathrm{kcal} /\left(\mathrm{kg} \cdot{ }^{0} \mathrm{C}\right)$.

The estimated hourly grid make-up during the tests is assumed as $0.5 \%$ of the aggregate pipeline capacity within the tested circulation loop.

The expected time of the water flow through the tested circulating loop is determined by the formula, $h$ :

$$
\tau_{\kappa}=\frac{V \cdot \rho \cdot 10^{-3}}{G_{t}}
$$

here $V$ - aggregate pipeline volume of the tested loop, $\mathrm{m}^{3} ; G_{t}$ - rated water consumption during the test, $t / h ; \rho$ - water density in the tested loop at the average water temperature.

Actual heat losses in the feeding and return pipelines for each section of the tested loop are determined by formulae, $\mathrm{kcal} / \mathrm{h}$ :

$$
\begin{aligned}
& Q_{f . t}=c \cdot\left(G_{c}-\frac{G_{f}}{4}\right) \cdot\left(t_{f}^{n}-t_{f}^{k}\right) \cdot 10^{3} \\
& Q_{r . t}=c \cdot\left(G_{c}-\frac{3 G_{f}}{4}\right) \cdot\left(t_{r}^{n}-t_{r}^{k}\right) \cdot 10^{3}
\end{aligned}
$$

here $G_{c}$ - average flow rate of the grid water in the feeding pipeline at the outlet of the CHP plant, $\mathrm{t} / \mathrm{h} ; G_{f}$ - average make-up water flow rate, $t / h ; t_{f}^{n}$ and $t_{r}^{f}$ - average water temperatures at both ends of the feeding pipeline in the section, ${ }^{0} \mathrm{C} ; t_{f}^{k}$ and $t_{r}{ }^{k}$-average water temperatures at both ends of the feeding pipeline in the section, ${ }^{0} \mathrm{C}$.

\section{Results}

Tests of the main pipelines from the CHP plant to the thermal chamber TC 6-21A were carried out in the period of June 18 till June 20. The temperature wave travel over the tested loop amounted to 25 hours and 40 minutes.

The average temperature of the grid water at the exit from the CHP unit was $73.8^{\circ} \mathrm{C}$, with the inlet temperature being $61.4{ }^{\circ} \mathrm{C}$. The water temperature at the end of the section at the 
circulation jumper in TC 6-21 was $67.6{ }^{\circ} \mathrm{C}$. Inside the thermal chamber TC 6-9 $t_{l}=70.7{ }^{0} \mathrm{C}$, $t_{l}=64.5{ }^{\circ} \mathrm{C}$.

Within the temperature wave mode, the maximum temperature of the grid water in the feeding pipeline at the outlet of the boiler plant was $85.2{ }^{\circ} \mathrm{C}$.

The average temperature of the ambient air within the testing period made up $t_{n}{ }^{m \cdot t}=16.0$ ${ }^{0} \mathrm{C}$, ground temperature at the middle laying depth made up $t_{g}^{m . t}=5.0{ }^{\circ} \mathrm{C}$.

The average flow rate of network water in the feeding pipeline at the outlet of the CHP plant was $84.6 \mathrm{t} / \mathrm{h}$, and the flow rate of make-up water was $6.0 \mathrm{t} / \mathrm{h}$.

Resulting from the instrumental measurements during the test:

$t_{a}{ }^{a . a}=4.6{ }^{0} \mathrm{C} ; t_{n}{ }^{m . t}=16.0{ }^{0} \mathrm{C} ; t_{f}^{a . a}=79.1{ }^{0} \mathrm{C} ; t_{r}{ }^{a . a}=48.9{ }^{0} \mathrm{C} ; G_{c}=84.6 \mathrm{t} / \mathrm{h} ; G_{f}=6.0 \mathrm{t} / \mathrm{h} ;$ $t_{f}^{n}=73.8{ }^{0} \mathrm{C}(\mathrm{CHP}) ; t_{f}=70.7{ }^{0} \mathrm{C}(\mathrm{TC} 6-9) ; t_{f}^{k}=67.6{ }^{0} \mathrm{C}(\mathrm{TC} 6-21 \mathrm{~A}) ; t_{r}{ }^{n}=67.6{ }^{0} \mathrm{C}(\mathrm{TC} 6-21 \mathrm{~A})$; $t_{r}=64.5^{\circ} \mathrm{C}(\mathrm{TC} 6-9) ; t_{r}{ }^{k}=61.4^{0} \mathrm{C}(\mathrm{CHP})$.

\section{Discussion}

The calculation findings of actual losses are summed up in Table 2.

Table 2. Calculation findings of actual losses.

\begin{tabular}{|l|c|c|c|c|}
\hline \multicolumn{1}{|c|}{ Network section } & $\begin{array}{c}\text { Estimated flow rate } \\
\text { for grid water, } t / h\end{array}$ & $\begin{array}{c}\text { Water temperature at the } \\
\text { beginning and end of the } \\
\text { section, }{ }^{0} \mathrm{C}, t_{f} t_{r}\end{array}$ & $\begin{array}{c}\text { Actual heat } \\
\text { losses, } \\
\mathrm{kcal} / \mathrm{h}\end{array}$ \\
\hline \multicolumn{5}{|c|}{ Feeding pipeline } \\
\hline CHP - downdrop to the duct & 83.1 & 73.8 & 71.4 & 199440 \\
\hline Downdrop to the duct - TC 6-9 & 83.1 & 71.4 & 70.7 & 58170 \\
\hline TC 6-9 - TC 6-13 & 83.1 & 70.7 & 69.2 & 124650 \\
\hline TC 6-13 - TC 6-15 & 83.1 & 69.2 & 69.0 & 16620 \\
\hline TC 6-15 - TC 6-19 & 83.1 & 69.0 & 68.1 & 74790 \\
\hline TC 6-19 - TC 6-21A & 83.1 & 68.1 & 67.6 & 41550 \\
\hline \multicolumn{5}{|c|}{ Return pipeline } \\
\hline TC 6-21 - TC 6-19 & 80.1 & 67.6 & 67.1 & 40050 \\
\hline TC 6-19 - TC 6-15 & 80.1 & 67.1 & 66.2 & 72090 \\
\hline TC 6-15 - TC 6-13 & 80.1 & 66.2 & 66.0 & 16020 \\
\hline TC 6-13 - TC 6-9 & 80.1 & 66.0 & 64.5 & 120150 \\
\hline TC 6-9 - downdrop to the duct & 80.1 & 64.5 & 63.8 & 56070 \\
\hline Downdrop to the duct - CHP-2 & 80.1 & 63.8 & 61.4 & 192240 \\
\hline
\end{tabular}

The actual heat losses for all tested sections of the heat supply network are converted to the annual average operating conditions using the formulae, $\mathrm{kcal} / \mathrm{h}$ :

$$
Q_{n . t}^{a . a}=\frac{Q_{f . t}\left(t_{f}^{a . a}-t_{g}^{a . a}\right)+Q_{r . t}\left(t_{r}^{a . a}-t_{g}^{a . a}\right)}{\frac{1}{4}\left(t_{f}^{n}+t_{f}^{k}+t_{r}^{n}+t_{r}^{k}\right)-t_{g . t}}
$$

for underground routing sections, total of the feeding and return pipelines:

$$
Q_{n . f . t}^{a . a}=\frac{Q_{f . t}\left(t_{f}^{a . a}-t_{a}^{a . a}\right)}{\frac{1}{2}\left(t_{f}^{n}+t_{f}^{k}\right)-t_{a . t}}, Q_{n . r . t}^{a . a}=\frac{Q_{r . t}\left(t_{r}^{a . a}-t_{a}^{a . a}\right)}{\frac{1}{2}\left(t_{r}^{n}+t_{r}^{k}\right)-t_{a . t}}
$$

here $t_{\text {g.t }}$ and $t_{a . t}$ - ground temperature and ambient temperature, average for the testing period, ${ }^{0} \mathrm{C}$.

Values of average annual heat losses by standards for the tested sections of a given heat supply network are determined according to formulae, $\mathrm{kcal} / \mathrm{h}$ :

- for underground routing sections: $Q_{n}{ }^{a \cdot a}=\Sigma \beta \cdot q_{n} \cdot L$;

- for above-ground routing sections: $Q_{n \cdot f}^{a \cdot a}=\Sigma \beta \cdot q_{n \cdot f} \cdot L$ and $Q_{n \cdot r}{ }^{a \cdot a}=\Sigma \beta \cdot q_{n . r} \cdot L$. 
The ratios of actual to norm-defined heat losses are determined by formulae:

- for underground routing sections $K=\frac{Q_{n . t}^{a . a}}{Q_{n}^{a . a}}$;

- for above-ground routing sections $K_{f}=\frac{Q_{n . f . t}^{a . a}}{Q_{n . f}^{a . a}}$ and $K_{r}=\frac{Q_{n . r . t}^{a . a}}{Q_{n . r}^{a . a}}$.

The calculation findings for average annual heat losses are summed up in Table 3.

Table 3. Calculation findings for average annual heat losses.

\begin{tabular}{|l|c|c|c|c|c|}
\hline \multicolumn{7}{|c|}{$\begin{array}{c}\text { Normative losses, Diameter, } \\
\text { Remarks }\end{array}$} & \multirow{2}{*}{ (year of routing) $l, \mathrm{~m} \beta q, \mathrm{kcal} / \mathrm{m} \cdot \mathrm{h} Q_{n}, \mathrm{kcal} / \mathrm{h}$} \\
\hline 800 (above-ground before 1990) & 974.5 & 1.15 & 173.76 & 194728 & Feeding pipeline \\
\hline 800 (above-ground before 1990) & 974.5 & 1.15 & 134.08 & 150260 & Return pipeline \\
\hline 800 (duct-type before 1990) & 240.0 & 1.15 & 323.24 & 89214 & \\
\hline \multicolumn{7}{|c|}{ TC 6-9- TC 6-21A } \\
\hline 700 (duct-type before 1990) & 559.0 & 1.15 & 289.68 & 186221 & \\
\hline 700 (duct-type before 2012) & 280.0 & 1.15 & 115.36 & 37146 & \\
\hline 700 (duct-type before 1990) & 331.1 & 1.15 & 289.68 & 110300 & \\
\hline 600 (duct-type before 1990) & 258.0 & 1.15 & 262.12 & 61192 & \\
\hline \multicolumn{7}{|c|}{ Total } \\
\hline
\end{tabular}

\section{Conclusions}

The comparison results for heat losses during the tests are stated in Table 4.

Table 4. Comparison results for heat losses during the tests.

\begin{tabular}{|l|c|c|c|}
\hline \multirow{2}{*}{ Network section } & $\begin{array}{c}\text { Actual heat losses } \\
\text { corrected to average } \\
\text { annual conditions, } \\
\mathrm{kcal} / \mathrm{h}\end{array}$ & $\begin{array}{c}\text { Norm-defined heat } \\
\text { losses corrected to } \\
\text { average annual } \\
\text { conditions, kcal/h }\end{array}$ & $\begin{array}{c}\text { Ratio } \\
\text { of actual to } \\
\text { norm-defined } \\
\text { heat losses, } K\end{array}$ \\
\hline CHP - downdrop to the duct & 262514 & 194728 & 1.35 \\
\cline { 2 - 4 } & 182752 & 150260 & 1.22 \\
\hline Downdrop to the duct - TC 6-9 & 108177 & 89214 & 1.21 \\
\hline TC 6-9 - TC 6-13 & 231808 & 186221 & 1.24 \\
\hline TC 6-13 - TC 6-15 & 30908 & 37146 & 0.83 \\
\hline TC 6-15-TC 6-19 & 139085 & 110300 & 1.26 \\
\hline TC 6-19-TC 6-21A & 77269 & 61192 & 1.26 \\
\hline
\end{tabular}

Following the result of heat supply network testing and finding processing, the actual heat losses exceed the norm-defined values by $1.21 \div 1.35$ times, except for the section TC 6-13- TC 6-15.

To reduce heat losses in heat supply networks, it is recommended to restore the partially destroyed thermal insulation of pipelines and fittings. When overhauling heat supply networks, use of the latest insulation materials, such as polyurethane foam, is recommended.

\section{References}

1. A. Yerominv, A. Kolosov. Modeling of energy efficient solutions regarding the heating system and the facade heat insulation in the implementation of thermomodernization, Eastern-European Journal of Enterprise Technologies 8, 91 (2018).

2. T. Teleszewski, D. Krawczyk, A. Rodero. Reduction of heat losses using quadruple 
heating pre-insulated networks: A case study, Energies 12, 24 (2019).

3. I. Akhmetova, N. Chichirova. Mathematical modeling of the process of determining the standards for process losses in the transfer of thermal energy of the coolant, Journal of Physics: Conference Series 891, 1 (2017).

4. E. Biryuzova, A. Glukhanov. Improving energy efficiency and reliability of heating networks through the use of multilayer thermal insulation structures, IOP Conference Series: Materials Science and Engineering 962, 3 (2020)

5. V. Krashchenko, N. Tretyakov, A. Chernov. Modeling and thermal calculation of a pipeline insulation system, E3S Web of Conferences 164, 14021 (2020).

6. A. Kluczek, P. Olszewski. Energy audits in industrial processes, Journal of Cleaner Production 4, 142 (2017).

7. I. Akhmetova, N. Chichirova, O. Derevianko. Revisiting heat losses calculation at district heating network, International Journal of Civil Engineering and Technology 8 (12), 694702 (2017).

8. Yu. M. Varfolomeev, O. Ya. Kokorin. Heating and heating networks (Moscow: INFRAM), 480 (2006).

9. A. Dalla Rosa, Li H., S. Svendsen. Method for optimal design of pipes for low-energy district heating, with focus on heat losses, Energy 36 (5), 2407-2418 (2011).

10. A. Helge, W.Sven. Essential improvements in future district heating systems, Energy Procedia 116, 217-225 (2017).

11. I. Zakirova, N. Chichirova. Experimental determination of effectiveness of thermal insulation of xperimental determination of effectiveness of thermal insulation of heating networks involving application of thin-film coatings, Safety and Reliability of Power Industry 10 (2), 143-149 (2017).

12. E. Biryuzova, A. Glukhanov. The influence of the method of laying pipelines on the energy efficiency of the heating network, Construction and Geotechnics 10 (2), 59-66 (2019).

13. Y.V. Nemirovsky, A.S. Mozgova. Two-dimensional steady-state heat conduction problem for heat networks, J. Phys.: Conf. Ser. 1359, 012138 (2019).

14. Y.V. Nemirovsky, A.S. Mozgova. Thermal conductivity of cylindrical tanks for backup fuel of boiler rooms, J. Phys.: Conf. Ser. 1382, 012139 (2019).

15. Y.V. Nemirovsky, A.S. Mozgova. Problems of thermal conductivity for storage tanks of liquefied gases and oil products, Journal of Physics: Conf. Series 1128, 012131 (2018).

16. Y.V. Nemirovsky, A.S. Mozgova. Problems of thermal conductivity of heat networks, Proceedings of the XI all-Russian scientific and technical conference «Topical issues of architecture and construction» (Novosibirsk: Novosibirsk state University of architecture and civil engineering), 9-15 (2018).

17. Y.V. Nemirovsky, A.S. Mozgova. Determination of heat losses in the section of the layered pipeline of heat networks, Bulletin of the Yakovlev Chuvash State Pedagogical University. Series: Mechanics of Limit State 2, 23-32 (2017).

18. A.S. Mozgova, A.V. Surikov. Energy inspection of boilers and heating networks, New Archit. Des. Build. Struct. Reconstr. Mater. III Int. (IX all-russian) Conf. 474-480 (2016)

19. A. Mozgova, T. Shennikova. Determination of the real energy efficiency of the inlet ventilation air heater and air curtain, IOP Conf. Ser. Mater. Sci. Eng. 890, 012147 (2020).

20. A.S. Mozgova. Problems of thermal conductivity of closed pressure vessels, Sci. Ind. defense. Proc. XIX All-Russian Sci. Tech. Conf. 4, 63-65 (2018).

21. A.S. Mozgova, T.V. Shchennikova. Test Results for Ventilation Units, IOP Conf. Ser. Mater. Sci. Eng. 1079, 042049 (2021).

22. A. Mozgova. Inspection of treatment systems at cogeneration plant, Contemporary Problems of Architecture and Construction, 381-384 (2021). 